\title{
Developing a quality curriculum in a technological era
}

\author{
Peter Twining $^{1}$ (D) Deirdre Butler ${ }^{2} \cdot$ Petra Fisser $^{3} \cdot$ Margaret Leahy $^{2} \cdot$ Chris Shelton $^{4}$. \\ Nadine Forget-Dubois ${ }^{5} \cdot$ Michel Lacasse $^{6}$
}

Accepted: 24 October 2020 / Published online: 11 November 2020

(c) Association for Educational Communications and Technology 2020

\begin{abstract}
There is considerable rhetoric internationally around the need for national curricula to reflect the changes that are taking place in the world outside school. This raises questions about what a quality curriculum in a technological era should look like, and equally challenging issues about how to achieve the necessary changes in schooling in order for such a curriculum to be realised. This paper summarises the views of 11 experts from seven countries. It introduces a sociocultural framework that highlights the complexity of achieving alignment between policies and practice spanning the national to local school to classroom levels. Three key issues that underpin alignment are then explored, each of which link with the issue of trust:
\end{abstract}

- stakeholders engagement;

- teacher professionalism;

- summative assessment.

By exploring and exemplifying these three issues the paper indicates potential ways of addressing them and provides 'tools to think with' to enhance future curriculum development initiatives.

Keywords Curriculum $\cdot$ Schools $\cdot$ Alignment $\cdot$ Partnership $\cdot$ Teacher professionalism . Assessment · Trust

Peter Twining

Peter.Twining@newcastle.edu.au

1 School of Education, The University of Newcastle, Hunter Building, University Drive, Callaghan, NSW 2308, Australia

2 School of STEM Education, Innovation \& Global Studies, DCU Institute of Education, St Patrick's Campus, Drumconda, Dublin, Ireland

3 College of Health Care of ROC van Twente, Hengelo, The Netherlands

4 University of Chichester, Bognor Regis Campus, Bognor Regis, Upper Bognor Road, West Sussex, UK

5 Conseil Supérieur de L'éducation, Gouvernement du Québec, Québec, QC, Canada

6 Université Laval, Department of Foundations and Practices in Education, Québec, QC, Canada 


\section{Context}

We live in a rapidly changing world that is struggling "to respond to economic, environmental and social transformations - including technological advances, climate change and migration" (OECD 2019, p. 9). These transformations, and in particular the impact of digital technologies, have increased demand for higher order skills, competencies and knowledge. They have also led to uncertainty about the future, for example: the potential impact of artificial intelligence on some workplaces; how to keep up with an accelerating pace of change; or how to manage global competition for skills (OECD 2019).

Within this global context, the school sector is expected not only to meet the demand for new, higher-order skills and competencies but also to prepare students to thrive in a future where the competencies and knowledge they will need to succeed are constantly changing. This is not about learning about digital technology per se, it is about how our digital era impacts on all aspects of schooling. Indeed, focussing on one aspect of the system, such as digital technology, without considering the system as a whole is unlikely to bring about sustained change (Butler et al. 2018).

In an effort to meet these challenges, many countries are re-designing their national curricula so as to better prepare young people now and in the future (Wolfenden et al. 2018). This begs the question 'What does a quality curriculum look like in a digital era?' That is the question that is the focus of this paper and that Technical Working Group 12 (TWG12) at EDUsummIT 2019 set out to answer. In so doing they needed to consider what educational visions, policies and practices might be most appropriate (Butler et al. 2018). This involved discussion of:

(a) What knowledge, competencies, attitudes and values today's school students need to thrive and shape their world (e.g. see Erstad and Voogt 2018).

(b) How school systems can develop such knowledge, competencies, attitudes and values effectively (e.g. OECD 2018).

However key to these discussions was developing an understanding of what is understood when we use the term 'curriculum' and how 'quality' is defined.

\section{What is understood by 'quality curriculum'}

The starting point for any consideration of 'quality curriculum' for schools must include a discussion of what is understood by the concept 'curriculum'. The word comes from Latin, where 'curriculum' (related to the verb currere, i.e. running) refers to a 'course' or 'track' to be followed. In the context of schooling, where learning is the central activity, the most obvious interpretation of the word curriculum is then to view it as a course, trajectory, or 'plan for learning' (cf. Taba 1962). However, this is a rather narrow view. van den Akker (2003) differentiates between different levels of curriculum:

- supra level: international debates or agreements on aims and quality of education

- macro level: curriculum at the system/society/nation/state level (e.g. national syllabi or core objectives)

- meso level: curriculum at the school/institution level (e.g. school-specific curriculum)

- micro level: curriculum at the classroom level (e.g. textbooks, instructional materials) 
- nano level: curriculum at the individual/personal level

Thus the process of curriculum development can be seen as narrow (developing a specific curricular product) or broad (a long term, ongoing process of curriculum improvement, often including many related aspects of educational change, such as teacher education, school development, and examinations). Building on UN Sustainable Develoment Goal 4 (United National General Assembly 2015) and Butler et al. (2018), a quality curriculum would be a 'plan for learning' which supports young people in acquiring the knowledge, competences and dispositions needed to be successful in the digital era. An important aspect of the digital era is growing global interconnectedness, and thus it makes sense to examine curriculum developments at the international (supra) level.

In a review of international trends and practices in curriculum development Walsh (2018) identified that one of the key characteristics of international practices (at the supra level) was the preparation of curriculum frameworks rather than prescribed curricula, allowing flexibility in interpretation and enactment at a national (macro) and school (meso) level. Such frameworks provide an insight into the key issues underlying curriculum development debates internationally. Two such curriculum frameworks which were explicitly developed in the light of understandings of the digital era are outlined below.

\section{OECD learning framework 2030}

The OECD Learning Framework 2030 (OECD 2018), which is summarised in Fig. 1, explicitly addresses the needs of individuals and of society. It is underpinned by a vision of "helping every learner develop as a whole person, fulfil his or her potential and help shape a shared future built on the well-being of individuals, communities and the planet" (p. 3).

This framework merges different views of knowledge (including 'knowledge about'/ content) with understanding different ways of making sense of the world and knowing how people act in different disciplines. This is combined with skills ('knowledge of') in the

The OECD Learning Framework 2030

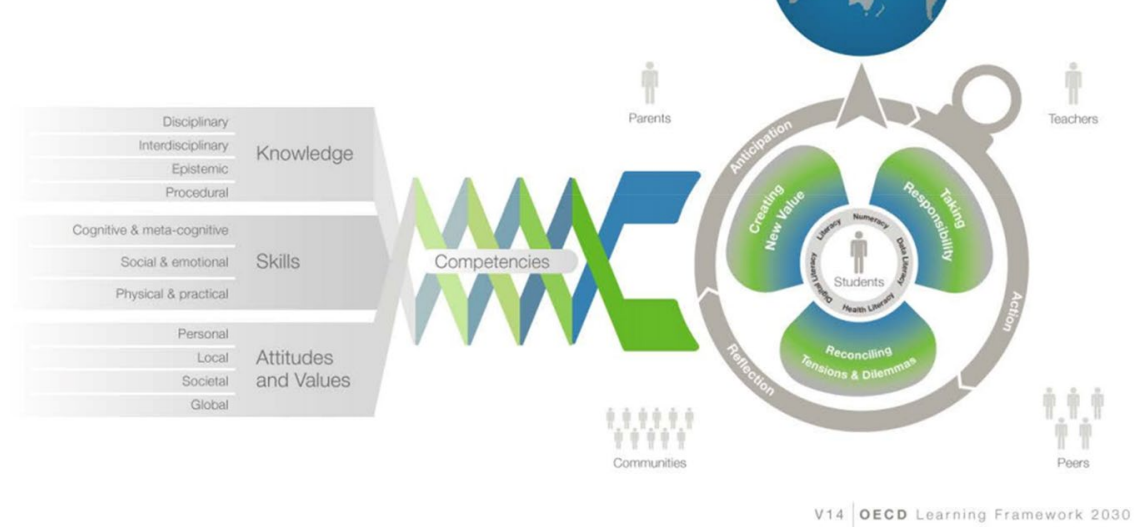

Fig. 1 The OECD Learning Framework 2030 (OECD 2018 p. 4) 
form of the application of knowledge to enable students to act in appropriate/valued ways in particular contexts. Attitudes and values are seen as mediating these different forms of knowledge. The combination of these three elements ('knowledge about', 'knowledge of', and values and attitudes) result in what the OECD refer to as competencies. This contrasts with traditional curricula in many school systems, which have tended to focus on 'knowledge about' (Biesta 2004).

Importantly, the OECD Framework recognises that the development of competencies requires changes in pedagogy, with a particular focus on increasing student agency.

\section{EU's key competences (European Commission 2018)}

The EU's Key Competences for Lifelong Learning includes eight key competences (see Fig. 2), which are identified as being "essential to citizens for personal fulfilment, a healthy and sustainable lifestyle, employability, active citizenship and social inclusion" (European Commission 2019, p. 4). As with the OECD framework there is a focus on both individual and societal needs, and a recognition that learning needs to go beyond content to include skills and attributes.

These supra level frameworks provide a useful starting point for discussions of "quality curriculum' at the national (macro) level.

Both the EU Key Competences Framework and the OECD Learning Framework 2030 are underpinned by views about the purposes of education that are encapsulated in their aims. In both cases these encompass individual performance and collective well being, which may be seen as being in tension with each other. Indeed, both frameworks see the purposes of education in terms of capacities, competencies or capabilities, so articulation is

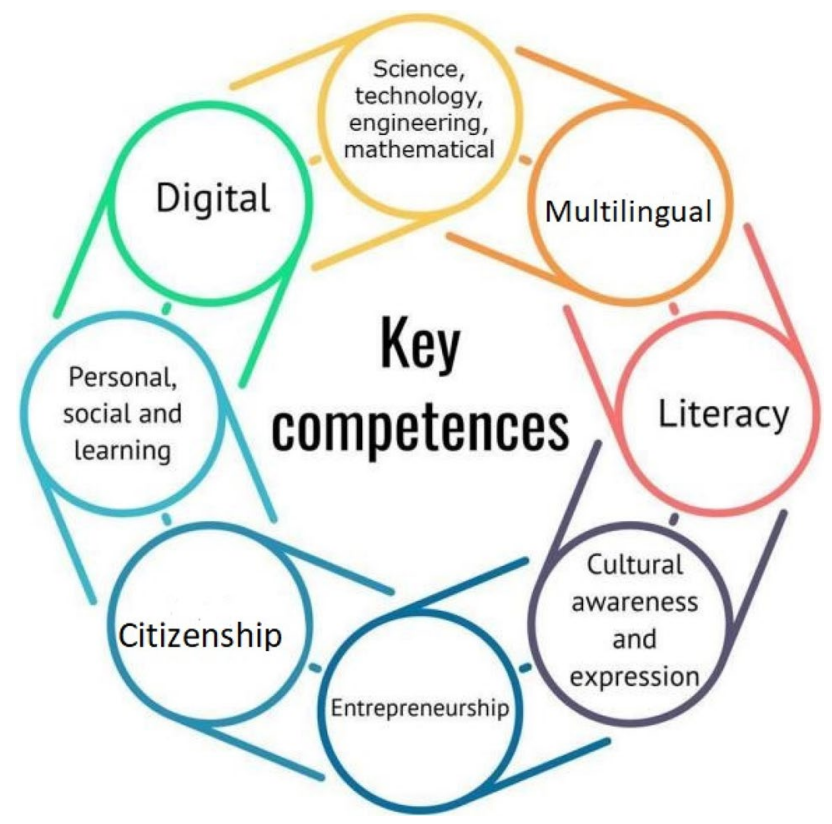

Fig. 2 The EU's eight key competences (European Commission 2018, p. 40) 
not "in terms of what the students should learn but in terms of what they should become" (Biesta and Priestley 2013, p. 4). This provides a stimulus for national curricula to think more broadly about what knowledge, competencies and dispositions school students need to thrive and shape their world (e.g. see Erstad and Voogt 2018) and thus should be included in a quality curriculum; i.e. a 'plan for learning' which supports young people in acquiring the knowledge, competences and dispositions needed to be successful in the digital era.

Having outlined the context, this paper will now examine the importance of purpose before exploring issues that arise when creating a quality curriculum in the digital era. The aim being to inform and hence enhance future curriculum development.

\section{The importance of purpose}

It has long been recognised that being clear about the purpose of schooling is critical (e.g. Goodlad 2006). The importance of defining the purpose of schooling however should not be confined to international frameworks but should be central to the development of curriculum at a national level.

For example, as part of the ongoing redesign of the Irish Primary School Curriculum, Walsh (2018) reviewed international trends and practices in curriculum development and stressed the need for clarity of purpose, aims and principles:

Central to the revised Overview must be an articulation of the purpose, aims and principles of the curriculum in Ireland. The inclusion of these elements will distinguish the curriculum from a syllabus, where the primary focus is on subject content. Being clear about this central purpose is imperative to ensure that all other elements of the curriculum, including the content, become subservient to this fundamental driver. (Walsh 2018, p. 16)

There is wide ranging support for the view that curriculum development essentially involves making decisions around what are considered to be the most important values and purposes for inclusion from the culture of a society (Lawton 1989).

Kelly (2004) advocated that curriculum developers should place their energies on articulating the ideological position and broad principles rather than defining specific content. Similarly, Biesta and Priestley (2013) noted that having explicit aims and purpose in the curriculum provides a rationale for the inclusion or exclusion of particular elements in a transparent manner. Furthermore, there is evidence from a cross-national study of nine jurisdictions that countries considered to have high performing education systems had clear and well thought through aims, principles and goals of education (Creese et al. 2016). However, it is clear that there are differences of views about the purposes of schooling across and within educational jurisdications (Butler et al. 2018).

Thus, the starting point for any discussion of curriculum needs to be an agreement about the purposes of schooling. While this idea is not new (e.g. Biesta and Priestly 2013; Kelly 2004; Lawton 1989; Tedesco et al. 2013) and may seem self-evident, in some instances it has not been the case. For example, the English National Curriculum's aims were added a number of years after the curriculum content and, as Alexander (2014, p. 160) points out, were little more than "a high-sounding statement you attach to the curriculum after you've determined its content and whose function is therefore cosmetic". In contrast, having a clear rationale, which informs your purpose, provides the major orientation point, to 
which other components of the curriculum should be linked. This applies at each level of the system. A way to present this visually is to arrange them as a spider's web (van den Akker 2003) (Fig. 3).

This curricular spider web not only illustrates the many interconnections between the components, but also its vulnerability. It illustrates that although the emphasis of curriculum design on specific components may vary over time, eventually some kind of alignment has to occur to maintain coherence, as each element is tied to the rationale at the centre. This coherence and alignment is often not evident within national curricula as outlined in the next section.

\section{Exploring issues relating to creating a quality curriculum}

As a starting point for their discussions members of TWG12 individually created blog posts that set out their personal views about what an ideal curriculum for the digital age would look like. They each then compared their 'ideal curriculum' with the reality of the curricula in their own country, which included: Australia, Canada (Quebec), England, Ireland, Sri Lanka, Slovakia, and The Netherlands. The data were analysed inductively, using Emergent Theme Analysis (Wong and Blandford 2002). This analysis foregrounded two issues:

- differences in the purposes and thus curriculum elements that group members were focussing on when thinking about their blog posts;

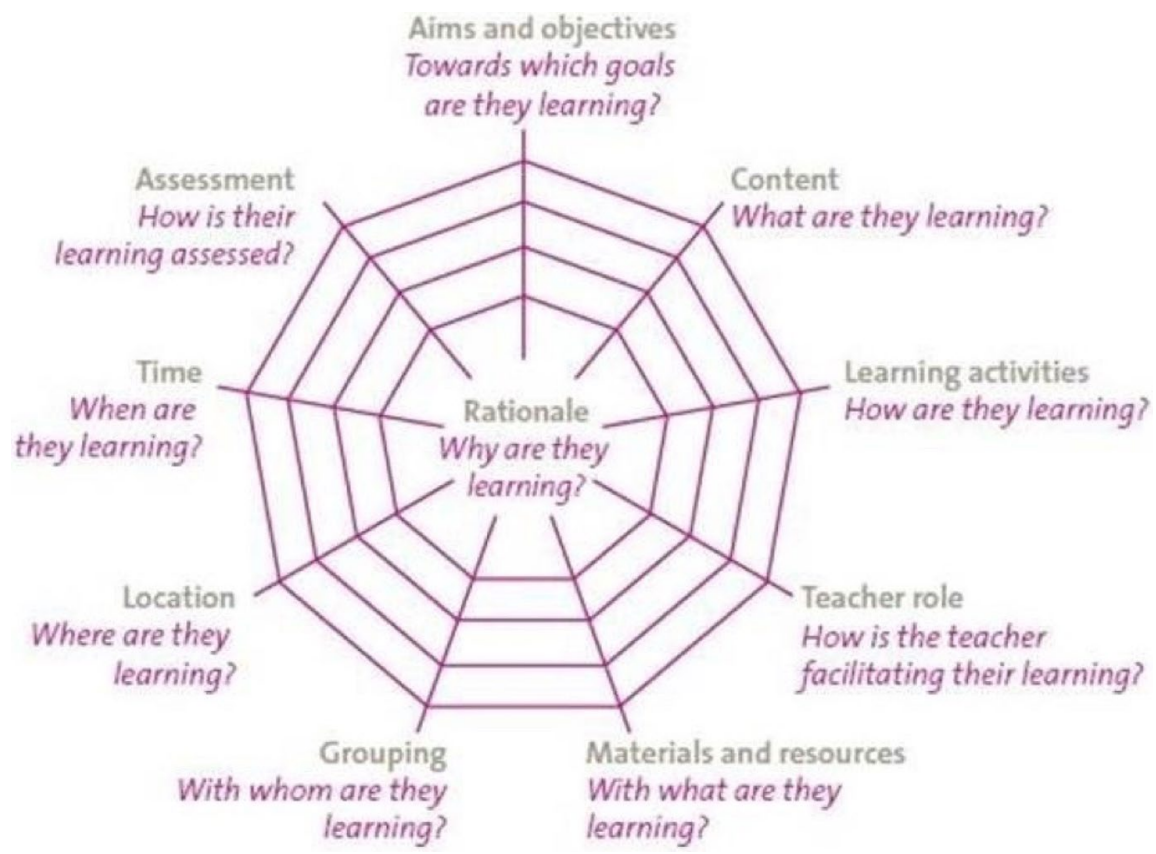

Fig. 3 A spider's web view of curriculum (van den Akker 2003, p. 4) 
- a clear disconnect between the visions of a quality curriculum within the blog posts and the realities of the curricula within the TWG12 members' countries.

Each of these is explored below.

\section{Purposes driving curriculum?}

Analysis of group members' blog posts highlighted differences in the underpinning purposes that group members were focussing on when thinking about their blog posts. For example, whilst some posts looked at the overarching aims of schooling, others focussed more narrowly on aspects of the curriculum explicitly linked to digital technology. In the subsequent group discussions it was agreed that the focus should be on that broader view. Building on the work of EDUsummIT 2017 (Butler et al. 2018), members of TWG12 adopted the Yin-Yang Vision Framework (Fig. 4). This sets out what the ultimate purpose of schooling should be and key elements that are necessary for the vision to be realised.

This framework is underpinned by a sociocultural theoretical perspective (Twining et al. 2017) which drew upon sociocultural theory as set out by Lave (1988), within which the concepts of Identity, Agency and Participation are key. The items on the left of the figure relate to Individual fulfilment. The items on the right focus on Universal wellbeing. The items in the middle are the capabilities that are necessary to achieve the vision as a whole, providing a bridge between the individual (Identity) and the collective (Participation). All of these dispositions and capabilities are developed through engagement with content. This content should reflect key concepts - powerful ideas that have relevance in multiple contexts and enable one to make sense of the world. For example, the notion of 'systems', which has relevance in biology (environmental systems, nervous system), wellbeing (health systems), business and IT (computer systems), and many other areas. Within this conception of curriculum the development of knowledge, skills and dispositions is seen as
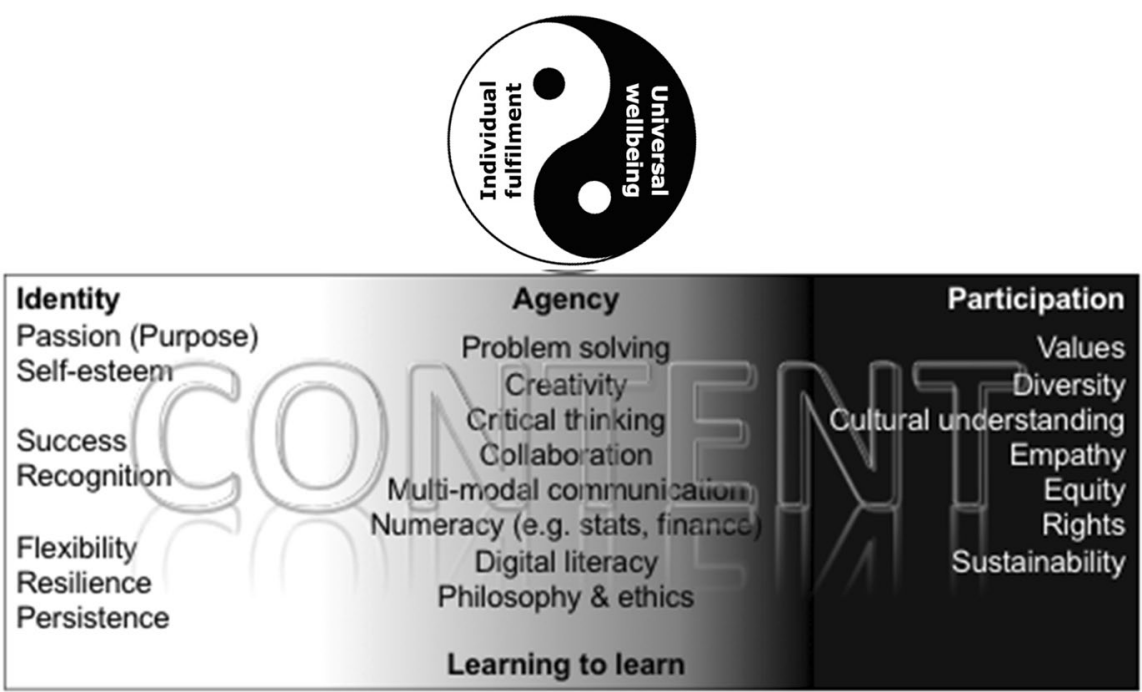

Fig. 4 The Yin-Yang Vision Framework (Twining 2019a) 
happening through engagement with key concepts which span discipline boundaries. This contrasts with traditional school curricula which tend to compartmentalise 'content' into discrete subjects that are often taught in isolation.

Underpinning this framework is a recognition that in order to achieve a vision of Individual fulfilment and Universal wellbeing you need to be able to apply your understandings in appropriate ways. This means that you need knowledge, capabilities and dispositions. We need to move away from a binary debate about content vs skills. Using the Yin-Yang Vision Framework, we believe could act as a bridge between supra (international) and macro (national) level curriculum debates, highlighting the importance of purpose, and providing a tool to think with at the macro and meso (school) levels.

\section{Curriculum disconnect}

The disconnect between TWG12 members' visions and the curricula realities in their school systems seemed to reflect tensions around the purposes of schooling in our rapidly changing world. This is mirrored in the gap between the dominant rhetoric of '21st Century Skills' and the reality of predominatly knowledge based curricula aligned with high stakes testing (e.g. NAPLAN) and international assessments (e.g. PISA) that cannot assess many of these critical skills and dispositions (ETAG 2015).

Butler et al. (2018) explored the issue of alignment, noting that this required alignment of purpose, policy (including curriculum, assessment, accountability and teacher professional learning), and practice at three levels (macro/national, meso/school, and micro/ teacher). Twining (2018) extended this analysis using a sociocultural framework (see Fig. 5).

This framework has three levels,

- The constitutive order - the broader context, including cultural norms, values and beliefs, as well as more explicit policies, rules and regulations. This includes any nationally specified curriculum.

- The arena - the enduring elements of the school context which are taken up from the constitutive order. For example, how policies and expectations at the national level

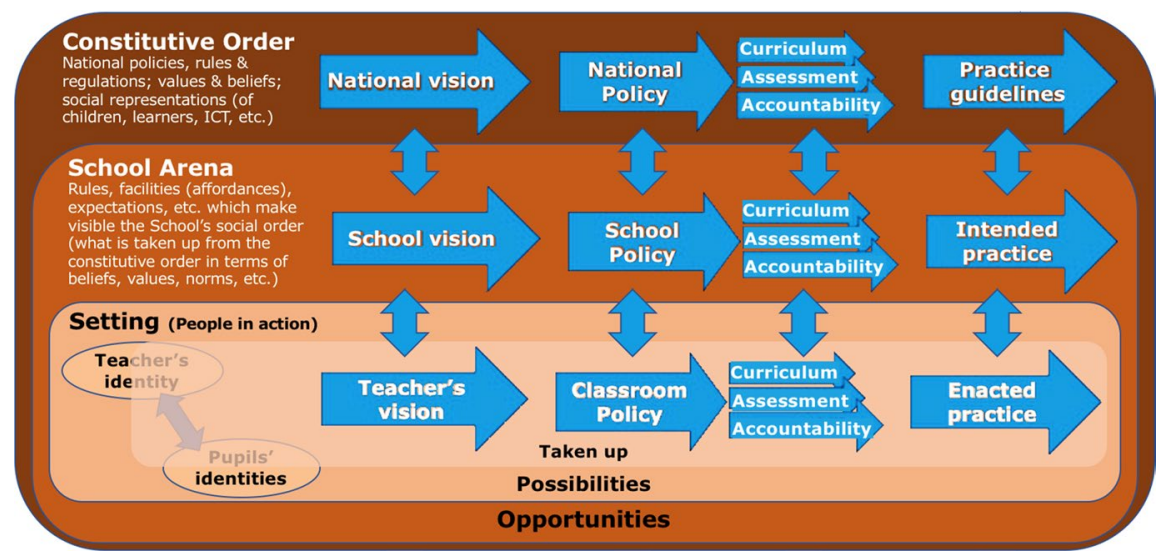

Fig. 5 Alignment within and across levels (Twining 2018) 
are interpreted and enshrined in the school expectations, policies and facilities. This includes any school specified curriculum (e.g. school schemes of work). The arena provides opportunities for action.

- The setting - the local context (e.g. the classroom) in which practice is implemented. At this level of analysis, the actors (e.g. teacher and students) perceive what is possible within the context of the school arena in the light of their identities. As illustrated by the shaded box within the setting in Fig. 5 actors 'take up' some of those perceived possibilities in their iterative interactions with the other people in their setting.

Achieving alignment between and within each of these levels (Constitutive Order, School Arena, and Setting) is complex. This reflects a tension in finding a reasonable balance between curriculum freedom and regulation when developing a quality curriculm.

Having agreed on the overarching Yin Yang Vision Framework TWG12 focussed on three key issues that need to be addressed in order to achieve alignment within and between levels. These key issues are stakeholder ownership, teacher professionalism, and assessment, each of which is explored below.

\section{Stakeholder ownership}

Curriculum development and alignment is a process with many stakeholders. Even though the stakeholders might have different values and interests in relation to the curriculum, it is important to involve them in a timely and authentic manner, to ensure commitment and ownership. In relation to broad curriculum development, van den Akker (2003) states that this is usually a long and cyclical process with many stakeholders and participants; in which motives and needs for changing the curriculum are formulated; ideas are specified in programmes and materials; and efforts are made to realise the intended changes in practice.

Members of TWG12 agreed that in order to ensure alignment between the specified and enacted curricula it was critical that all stakeholders should be involved in co-constructing the curriculum; including agreeing the purposes that the curriculum is intended to meet. Table 1 illustrates the key stakeholders at each level of alignment.

Table 1 Key stakeholders at each level of alignment

\begin{tabular}{ll}
\hline Level & Examples of stakeholders \\
\hline Constitutive order & $\begin{array}{c}\text { Politicians \& policy-makers; national agencies; representative bodies including } \\
\text { religious bodies, teachers' unions, and special interest groups; lobbying groups; } \\
\text { education experts; and individuals and organisations responding to consultations }\end{array}$ \\
Arena & $\begin{array}{l}\text { School management groups (e.g. local authorities, Trusts; Chains of independent } \\
\text { schools); local representatives of the community including religious leaders, busi- } \\
\text { ness representatives, and community groups; school leaders; teachers and other } \\
\text { staff; parents and students } \\
\text { Setting }\end{array}$ \\
& Classroom teachers; ancilory and other staff working in schools; parents (as a major \\
& influence on cultural capital of children so influencing possibilities); and students \\
\hline
\end{tabular}


At every level there are large numbers of stakeholders. The nature of those stakeholders changes between levels, with their foci becoming more local and immediate as you move from the Constitutive order to Arena to Setting.

Teachers are a particularly important group because ultimately they enact a curriculum at the Setting level. Involving them in the curriculum development process can help address the challenge of clarity and hold:

- clarity, in the sense of having a shared understanding about what needs to be learnt, and

- hold in the sense of ensuring alignment between the specified curriculum and what is enacted in the Setting.

The consequence of misalignment between curriculum purposes and curriculum practices can be seen in Donaldson's (2015) report on the National Curriculum in Wales. Donaldson's suggestions for improving the curriculum were based on an analysis of the problems of the previous curriculum in Wales. Donaldson notes that a highly prescriptive curriculum combined with powerful legislative and accountability mechanisms led to "much of the curriculum as experienced by children and young people has become detached from its avowed aims and too focused on the short-term" (p. 10). Donaldson's approach to addressing these problems and to align curriculum, assessment and accountability was to "involve as many people in Wales as possible" (2015, p. 13). However, how to organise involving as many stakeholders as possible is a thorny issue. So it is useful to learn and build on what other countries have tried as outlined in the example below from the Netherlands.

\section{How to overcome the issue: an example from the Netherlands}

The Netherlands is an example which illustrates a range of typical approaches to tackling the problems and tensions of trying to address the shifting priorities of society particularly in relation to the use of digital technologies and how to accommodate their use in the school curriculum. However, what is unique is how the focus came round to having a national discussion on the future of schooling.

Since the 1980s/90 s, 'information science' and 'informatics' was part of the national curriculum in the Netherlands, this was:

(a) particularly the case in secondary schooling and;

(b) primarily focused on understanding and being able to work with computers and programming.

These subjects eventually proved very difficult to implement and they disappeared in 2000 from the curriculum (Voogt and ten Brummelhuis 2014). The discussion about ICT in schooling gradually changed from learning about ICT to using ICT for learning, and more and more attention was paid to the integration of ICT in schooling as a "tool" for teachers.

However a report from the Royal Netherlands Academy of Arts and Sciences (KNAW 2013) stated that the increasing digitisation of information and communication in society required new skills but that these skills (Digital Literacy) were not getting sufficient attention in schooling. This report ignited the discussion again with regard to the role and use of digital technologies in schools. This focus, coupled with a range of other issues which were 
gaining attention (such as twenty-first century skills, equity, and the perceived overload of the current curriculum), led to a broad national discussion about the future of schooling in the Netherlands.

In November 2014, the State Secretary for Education, Culture and Science of the Netherlands officially launched an online countrywide consultation about the future of primary and secondary schooling. Everyone in the Netherlands had the opportunity to take part. The board consultation process outlined in Fig. 6 was the start of a process of curriculum design. This consultative process was an effort to garner the views of as wide a range of stakeholders as possible to begin the process of reaching an agreement on a shared common purpose for the curriculum (rationale in terms of the spider web). For example, via social media over 16,000 people contributed their ideas on what the young students of today should learn if they are to be productive members of society in the year 2032 . Based on the consultation an independent commission, Platform Onderwijs2032, wrote an advisory report about future-oriented education in the Netherlands which they presented in January 2016 to the State Secretary, this was meant as an overall rationale for the ongoing curriculum review. Next to the importance of specific content domains such as Language, Science, Numeracy and Social Studies they concluded that Citizenship and Digital Literacy should also be part of the formal curriculum (Platform Onderwijs2032 2016).

Conscious of building a shared understanding of a common purpose to underpin the curriculum, it took a year to discuss the report with pupils, teachers, parents, school leaders, administrators, scientists, representatives of social and cultural organizations, business and political parties (Platform Onderwijs2032 2016). Based on these discussions parliament agreed that a new curriculum for the primary and secondary school sector was needed and in 2018 the process to develop this was started. Based on the consultative process this new curriculum would consist of nine subjects: Dutch, Arithmetic/mathematics, English/ modern foreign languages, Exercise \& Sport, Art \& Culture, Human \& Nature, Human \& Society, Citizenship, and Digital Literacy.

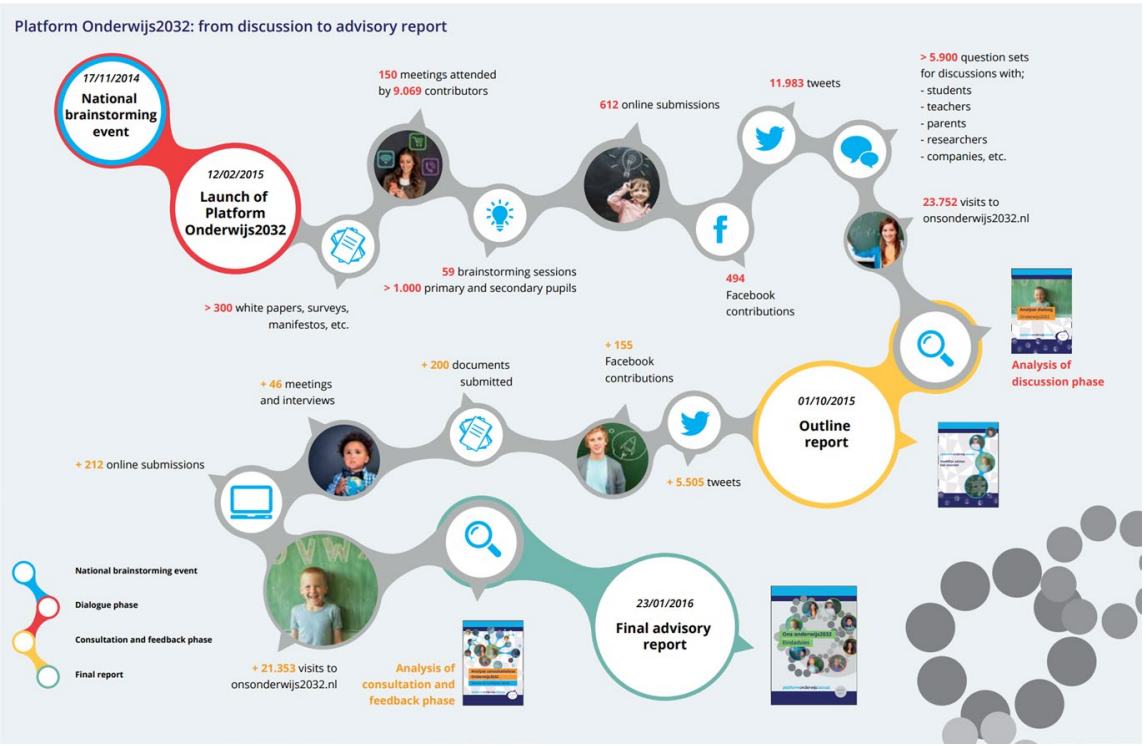

Fig. 6 The Netherlands Curriculum Consultation Process (Platform Onderwijs2032 2016, p. 19) 
The next stage of the curriculum design process is particularly difficult in a co-constructive process. There is always a challenge to get a balance between involving everyone and making sure you have a workable situation. What the Dutch example illustrates is what a government and the coordination group accomplished by letting the teacher design teams do the work and giving all others the opportunity to react.

As a starting point, 125 teachers and 18 school leaders were recruited to work on the new curriculum. For each subject a teacher design team (TDT) was formed to work on a subject. The TDT worked together in six three-day sessions. After each three-day session, the documents they had produced were open for online consultation. Everyone with an interest in the various subjects was able to react to the documents. Next to the general consultation rounds, all documents were discussed with the specific "subject associations". These associations are groups of experts from a specific subject.

The reactions/feedback was not taken for granted. Everything was read and either included in the documents or - when decided that it should not be included - arguments were given for why it was omitted.

In addition, a special working group on "coherence" with experts from the national expertise centre for curriculum development analysed all documents from all working groups to see if the big ideas and the key stages or learning trajectories were a) in line with the rationale and $b$ ) in line with each other.

Taking Digital Literacy as an example, a teacher design team consisting of 13 teachers, two school leaders, and two members of the national institute for curriculum development built a vision for the subject, designed big ideas, and corresponding learning trajectories for the big ideas (Ontwikkelteam Digitale Geletterdheid 2019). The TDT defined Digital Literacy as the skills that relate to using ICT effectively, efficiently and responsibly. They involve a combination of ICT (basic) skills, computational thinking, media literacy and information literacy (Thijs et al. 2014).

Big ideas (also known as essential understandings) are broad statements that frame what students will learn (Government of Alberta 2019). Eight big ideas were described by the TDT: (1) data and information, (2) safety and privacy, (3) using and controlling, (4) communication and cooperation, (5) digital citizenship, (6) digital economy, (7) applying and designing, and (8) sustainability.

In order to help teachers from primary and secondary schooling to teach the concepts of Digital Literacy key stages or learning trajectories needed to be designed. Learning trajectories were defined as "a reasoned structured set of intermediate objectives and content leading to a certain core objective" (Strijker 2010, p. 10). Learning trajectories not only describe what students should learn, providing clarity about the core objective, but also afford the opportunity to personalise learning by adjusting learning goals and related learning activities to the needs of the learners. The TDT concluded that Digital Literacy should be both a separate subject and embedded as a cross-curricular theme across all disciplines.

Taking all the feedback at each stage into consideration, the TDT for Digital Literacy published their final version of the vision, big ideas and learning trajectories in June 2019. The products of all TDTs were combined into a final report that was sent to parliament in October 2019. After discussions in parliament the decision was made to start with the next stage of curriculum development for primary and lower secondary schools: making the learning trajectories and goals part of the legal and mandatory framework for primary and lower secondary schooling in the Netherlands. Working with teacher design teams again, teachers, school leaders and teacher trainers will work together, supported by experts from the national expertise centre for curriculum development to complete this next stage of 
curriculum development. It is expected that the new curriculum will be put into practice in 2022 .

There are a wide range of groups and individuals who can make a strongly justified claim to be a key stakeholder in schooling and thus have a right and a responsibility to contribute to the curriculum design process. While the approach taken in the Netherlands ensures that teacher design teams are at the core of the curriculum reform, we need to pay particular attention to the wider body of teachers who, although given the opportunity to contribute to consultations, may have been less directly involved in the overall curriculum design. These teachers form a particularly significant stakeholder group because of their direct control over how curriculum intentions and expectations are actualised in classroom teaching and learning activities (at the Setting level).

\section{Teacher professionalism}

The second key challenge relates to the role and professional status of the school teacher in the enactment of any new curriculum at the Setting level. Accepting that teachers are central to the adoption of any curriculum reform (Kärkkäinen 2012; Schoenfeld 2014), does not just require teacher 'buy in' but recognition of what it takes to develop ownership by the teaching profession of any new curriculum or curriculum innovation. In considering the schooling system as a whole (Constitutive Order, School Arena, Setting), the challenge is therefore how to capture and build on the expertise of teachers so that they become invested and genuinely participative in curriculum reform, thus ensuring that intended curriculum aims are achieved in practice. The extent to which teachers adhere to the specified curriculum and have control over classroom activities will vary between countries, local school systems, and within individual schools. This relates to the professional status of the teacher in their context and directly impacts on the effectiveness of any attempt at curriculum reform.

The TALIS 2018 (OECD 2020) teacher survey suggests that although teachers in most countries have a large degree of autonomy over their practice in the classroom, they still have significant challenges ahead of them. Only $14 \%$ of teachers in the 48 countries surveyed say that policy makers in their country/region value their view, and only $24 \%$ believe that they can influence education policy. This reflects a lack of trust of teachers, which emerged as active distrust in the later part of the twentieth century followed by a focus on achievement data and top-down measures that emphasised performance targets and public scrutiny (Hargreaves and Shirley 2009). The implications according to Schleicher (2020, p. 31) are that teachers "rarely own their professional standards to the extent other professionals do, and rarely work with the level of autonomy and in the collaborative culture that people in other knowledge-based professions take for granted".

Decades of research show that curriculum reform does not automatically result in sustainable changes in the everyday practices of schools (Fullan and Miles 1992) and that how reform is implemented plays a key role in determining whether an intended curriculum achieves its desired outcomes (McLaughlin 1990; Tuinamuana 2011). It is also well documented that teachers have a central role in the successful adoption of any curriculum reform (Kärkkäinen 2012; Schoenfeld 2014) and that new curricula are often not implemented as planned. This lack of implementation as planned is due in large part to conflicts between the principles of a new curriculum and teachers' existing beliefs and practices about teaching (Orafi and Borg 2009). A new curriculum may demand significant shift in thinking and practice which according to Prendergast and Treacy (2018) leads to concerns 
among teachers on issues such as the reasoning behind the reform, the implications for classroom practices and students, as well as their ability to implement the changes. Thus, educators may implement the reform with fidelity by following the curriculum as prescribed, adapt the curriculum to the local context while adhering to its core principles, comply with the curriculum by only implementing surface-level changes, co-opt the curriculum to fit with existing practices, or not implement the curriculum at all (Berman and McLoughlin 1976; Tichnor-Wagner et al. 2018; both cited in Taguma and Barrera 2019).

There are two possible conceptions of the role of the teacher in transacting a curriculum: to view teachers as technicians whose job is to deliver what others have decided, or to treat teachers as professionals who are best placed to ensure that schooling meets the aims that society has agreed on. The first view, a top-down, centralised approach where policymakers or curriculum designers seek compliance from implementers on the ground (e.g. teachers) to carry out their directives without any alterations to the intended curriculum design, can lead to teacher de-professionalisation as the judgement of teachers is seen to no longer be valuable (Ball 2008). It can be enacted through attempts to 'teacher-proof' the curriculum via overly-prescriptive lesson plans or scripts based on a "theoretical assumption that ... the behaviour of teachers needs to be controlled and made consistent and predictable across different schools and student populations" (Giroux 2002, p. 2). However, such attempts can have negative consequences, including reducing teachers to 'task managers' rather than 'concept/skill builders' who are concerned with the pupils' deep learning of knowledge and skills (Twistleton 2004). It leads to the erosion of teacher autonomy, along with their personal and professional identities (Day 2002). Ultimately teachers' knowledge and professional practices are diminished (Giroux 2010; Fitzgerald and Knipe 2016; McLaren and Farahmandpur 2006).

As Pollard (2010) suggests, pedagogy is 'impoverished' (p. 5) if teachers are unable to engage in curriculum development. The de-professionalisation of teaching has happened in many countries (Rubin 2011; Rubtcova et al. 2015). According to Priestley et al. (2012, p. 192) this control over schooling "could be seen as the result of such systems having been subject for at least two decades to the combined influence of prescriptive national curricula and the use of outcomes steering, both backed by rigorous inspection regimes and the quantitative use of attainment data".

In the UK for example, in his summary of findings from the Cambridge Primary Review, Alexander (2010, p. 7) states that "in many primary (UK) schools a professional culture of excitement, inventiveness and healthy scepticism has been supplanted by one of dependency, compliance and even fear; and the approach may in some cases have depressed both standards of learning and the quality of teaching". In Portugal, Teodoro and Estrela (2010, p. 636) report that teacher autonomy was "progressively removed with the emergence of administrative control of the curriculum". While in the USA, Au (2011, p. 30) claims that 'teachers' power' [is] being increasingly usurped through policy and curriculum structure. This erosion of the teaching profession and deprofessionalising of the teacher now presents as a serious challenge and both reflects and undermines trust in teachers.

Recent trends in curriculum development have placed greater emphasis on the formulation of curricula in terms of competences and capacities and on the teacher as a central agent in curriculum development (Priestley and Biesta 2013; Sinnema and Aitken 2014). The focus on twenty-first century skills and competences has been identified in various comparative analyses of curriculum (e.g. Creese et al. 2016). Trends towards school-based curriculum within a central framework (Kärkkäinen 2012) and an outcomes-based educational approach (Biesta et al. 2015) have also been idenified. Many countries have accordingly prepared curriculum frameworks rather than prescribed curricula. Such frameworks 
allow flexibility in interpretation and enactment at teacher level. For example, Priestley and Sinnema (2014) found that current curriculum policies in New Zealand and Scotland are characterised by flexibility at both national and school levels. Similarly, in Quebec, the Ministry of Education's digital action plan measures for how digital technology might be used are presented as suggestions, although the use of digital technologies in teaching and learning is required. Ireland also has a Digital Learning Framework (Department of Education and Skills 2017a, b) which is comprised of standards and statements of practice for embedding digital technologies in teaching. However, it is up to schools and teachers to decide which statements to focus on.

These changes represent a shift in emphasis from teachers as 'curriculum implementers' to 'curriculum developers and co-constructors'. However, this shift not only places the teacher at the centre of curriculum development but accentuates the importance of teacher capacity and autonomy (Biesta et al. 2015). The challenge is how to gain the 'buy-in' of teachers so that they become invested in and develop ownership of the reform. While it is suggested that embracing a culture of trust and autonomy, and promoting teachers' agency over the curriculum reform, increases teachers' engagement in the reform work (McCharen et al. 2011; Priestley 2011); it is accepted that teachers are often not fully engaged in the consultation process when decisions are made in relation to curriculum (e.g. Elliott 1994; Williamson 2017). This is significant when one considers that teachers' expertise and attitudes, including their understanding of the reform, contributes to the way the reform is implemented (Tikkanen et al. 2017). In addition, tensions continue to exist in this form of curriculum development between the autonomy proffered to teachers as curriculum developers and the control and accountability mechanisms of the wider system (Biesta and Priestley 2013).

\section{Issues to be considered}

This raises questions about how to re-professionalise teaching and hence increase trust of teachers. Fundamentally this is about ensuring that teachers are treated and act like profesionals. The key characteristics of professionals include:

- being knowlegable about the underpinning principles and theories in your field;

- having expertise in curriculum and assessment enactment;

- engaging in regular professional learning and re-acreditation;

- being the creators and curators of knowledge in your field;

- working the hours necessary to perform their role rather than a fixed number of hours;

- having a high degree of autonomy, within the bounds of agreed professional standards;

- having a independent professional body that oversees the professional standards.

The first four of these are closely linked to pre-service and continuing professional learning. Based on evidence from the literature Twining and Henry (2014) identitied key characteristics of effective professional learning (see Fig. 7)—it should be:

- strategic-involving the senior management team, linking with the school development plan, and being integrated with the school's self-review and/or performance management processes;

- impact focussed - in terms of enhancing curriculum, pedagogy, and/or learning outcomes;

- context relevant - related to the needs of the staff and students and using resources/ equipment available in the school; 


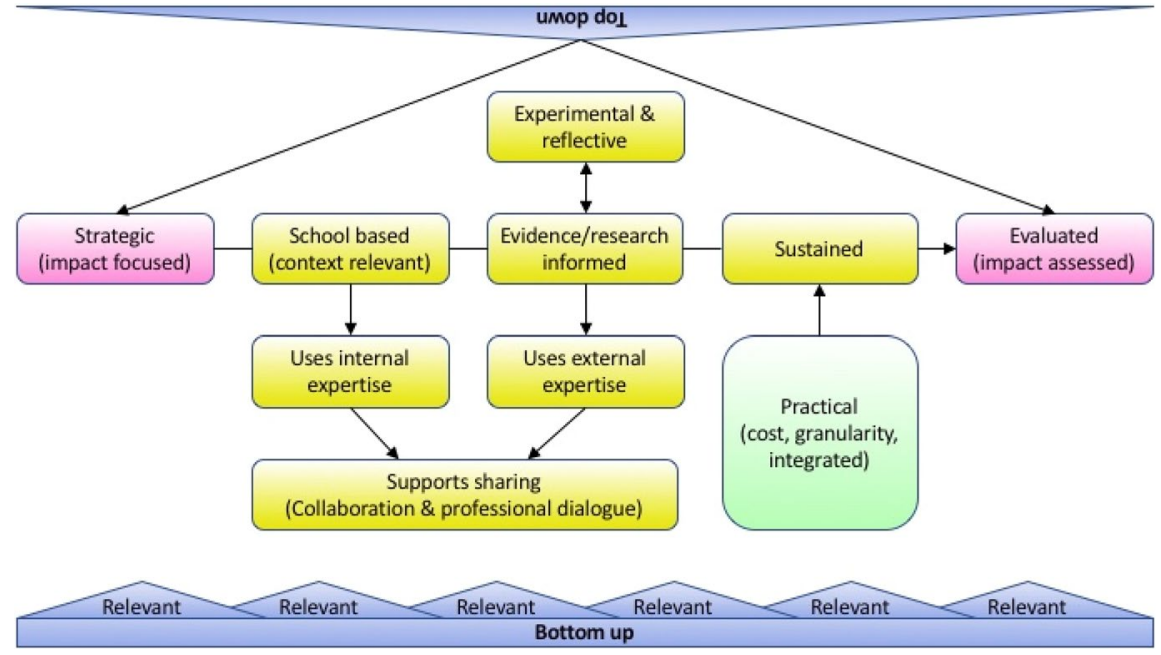

Fig. 7 Characteristics of effective teacher professional learning (Twining 2019b)

- informed by both internal expertise (e.g. school staff) and external expertise (e.g. consultants);

- collaborative - supporting sharing and professional dialogue;

- experimental and reflective - trying out new ways of working and reflecting collectively on practice;

- sustained rather than one-off;

- evaluated in relation to planned impact.

Practitioner research can encapsulate all of those elements, and positions teachers as the creators of their professional knowledge base (Twining and Henry 2014).

The last three characteristics of professionals relate to the regulation and autonomy of the field. The key challenge here is how to uncouple education policy (at the Constitutive order level) from short-term political control. Finland, which is widely recognised as being one of the more successful education systems in the world, has a model in which schools have considerable autonomy (World Bank 2012, p. 1). They note two key factors that underpin the success of the Finnish education system: "The two most important factors explaining the success of the Finnish education system are: (i) education has been a national priority for decades, and (ii) the system operates on trust."

Trust (or lack of it) and summative assessment are closely linked.

\section{Summative assessment}

As stated in the introduction, the word curriculum is related to the Latin verb currere, which means course or track to be followed. In schooling contexts summative assessment is sometimes seen as the finish line of a race. Indeed, summative assessment generally drives practice in schools irrespective of what the curriculum specifies (e.g. Conseil supérieur de l'éducation 2018; ETAG 2015) and thus, where something is not being assessed it is likely not to be a priority (Robinson and Aronica 2015). The pressure to improve student performance on mandated tests diminishes teachers' authority and control over what and 
how they teach (Au 2011; Wills and Sandholtz 2009). Fundamentally, there are two main issues with current forms of summative assessment.

The first issue is that summative assessments are often used not only to establish what students have learnt, but also as indicators of the quality of the educational provision (e.g. Klenowski 2015). Thus, teachers focus on summative assessment because that is what they are held accountable against (ETAG 2015). Berliner (2011) highlights that this can have a range of negative educational impacts. Such impacts include: off-rolling students; holding students back by a year; focussing on students who are on grade boundaries; cheating; narrowing the curriculum; and teaching to the test. This problem could be overcome by separating out the evaluation of the quality of school provision from the assessment of what young people have learnt.

The second issue is that traditional forms of summative assessment are unable to capture evidence of many of the competences and dispostions that are valued as being essential today if schools are going to succeed in enhancing individual fulfilment and universal wellbeing. The fact that summative assessments, especially national assessments, are determinant for pupils' access to higher education (e.g. A levels in England; HSCs in Australia; the Leaving Certificate in Ireland) results in too narrow a focus on academic understanding at the expense of other critical competences and dispositions. High stakes testing replaces trust in teachers' professional judgment.

Summative assessment is of course important for selection and certification purposes. The challenge is how to assess the competences and dispositions that are seen as being essential, as well as the knowledge that current high stakes assessments focus on. We need to develop new forms of summative assessment that complement existing ones, and align with the purposes of schooling. Whilst this would increase the validity of school assessment in the sense of measuring the things that are important, achieving this raises many challenges as well as opportunities (Webb and Ifenthaler 2018), including potentially reducing construct validity and reliability. Thus, for example, including teacher judgements of practical performance, such as in a science experiment, would increase the validity of a science assessment. However, it would also increase the risk of inter-marker inconsistency, which would need to be mitigated by some form of moderation process.

\section{Issues to be considered}

This highlights three key issues that are explored further below:

- Criteria for evaluating summative assessment

- Approaches to complementing traditional forms of assessment including emerging possibilities

- Teachers professional learning to enable them to design assessment tasks

Twining (2020a) set out criteria for evaluating summative assessment of young people's learning. These include being:

- relevant - this is an aspect of validity: summative assessment needs to measure things that are important (i.e. the goals identified in the curriculum)

- credible - this combines aspects of validity (measuring what it claims to measure) and reliability (being both accurate and consistent)

- practical - it must be feasible to implement, and ideally integral to the learning process 
- scalable - it must be able to be used with large numbers of learners

- formative - assessment should inform future learning as well as providing a summary of current knowledge, competences and dispositions

- positive - it should be constructive, and focus on success rather than failure

- ethical, including:

- it should enable everyone to succeed by being at an appropriate level and/or providing alternative pathways to success. Norm based assessment is unethical because it requires that some people fail in order for others to succeed

- it should be transparent - both in the sense of not being covert and being clear why particular judgements have been made

- it should be unbiased - it should not favour particular individuals

- able to be reported concisely - this is important because recruiters and admissions officers typically don't have time to read through copious documentation about student performance

A number of approaches to complementing traditional forms of assessment have been developed, including: portfolios, eExams and digital badges.

Portfolios, can support reflection and self-assessment. At the Junior Cycle (15 year olds) in Ireland there has been a shift towards the use of portfolios in place of traditional examinations. Whilst they can provide rich evidence of achievement, that can be mapped to standards, they are time consuming to mark or evaluate.

Digital badges, and other forms of micro credentials, can provide certification for competencies and dispostions which may have been developed either within or outside formal schooling. They suffer from a lack of standardisation, which potentially undermines their credibility.

eExams, which use the power of digital technology, potentially enable students to demonstrate competences and dispositions (ETAG 2015), for example through the use of simulations. However, the pragmatics of moving to eExams are considerable. For example, in a school context where all students studying a particular subject need to take their exam at the same time and in 'exam conditions', as is common for high stakes tests, most schools do not have the necessary infrastructure (e.g. hundreds of devices and robust Internet). Approaches to addressing this challenge have been developed, based on a bring your own (BYO) device model (e.g. Fluck and Hillier 2016), but have not gained traction in schools.

There are also a number of emerging possibilities, including:

- Point of Learning (PoL) which is a new approach to collecting compelling evidence of competences and dispositions in the form of 'claims' based on observations of practice by multiple people over prolonged periods (Twining, Rix and Sheehy 2016).

- Social Learning Analytics which utilises AI, and in particular data mining techniques to assess learning in online environments (e.g. see Twining 2019c).

- The use of online 'living CVs' which include endorsements and recommendations from members of the learner's community both inside and outside school (e.g. Twining 2020b). This reflects how adults use LinkedIn to develop their professional profiles and networks. 
One way to start to develop new approaches to assessment would be to ensure that teachers are better educated to design assessment tasks. Whilst in some countries teacher education provision does focus on assessment, this tends to be formative rather than summative assessment. In other jurisdictions, such as Quebec, there are very few courses dedicated to assessment in teachers' professional learning programmes, and what there are tend to be disconnected from courses about teaching subjects (Conseil supérieur de l'éducation 2018).

Unless solutions are found to 'the assessment problem', the gap between the rhetoric of national curricula and the reality of practice in schools will remain.

\section{Conclusions}

There is a growing consensus that current school curricula are not meeting the needs of individuals or society. If we are going to strive for a vision of Individual fulfilment and Universal wellbeing then the curriculum needs to prepare young people to influence the world outside school and to tackle the wicked challenges that humanity faces. In short, the curriculum needs to follow purpose. This means that we need to change the predominantly content focus of traditional curricula so that they encompass knowledge, competences and dispositions. That of course has knock on implications for many other aspects of educational provision, as highlighted in the spider web of inter-relationships (Fig. 1).

We also need to recognise that a curriculum that genuinely focusses on learners having the ability to act outside school will require not just a change in curriculum but also in pedagogy. However a change in pedagogy won't be enough if the teacher is not recognised and respected as a professional who has an active role in determining the curriculum and how learning is to be assessed. Furthermore, we need to recognise that it doesn't matter what the curriculum says if it is not aligned with summative assessment and does not have the buy in of key stakeholders.

In exploring the development of a quality curriculum in the digital era, this paper has clarified that a quality curriculum is one that supports young people in acquiring the knowledge, competences and dispositions needed to be successful in the digital era. The Yin-Yang Vision Framework was introduced, as a bridge between supra (international) and macro (national) level curriculum debates, that highlights the importance of purpose, and provides a tool to think with at the macro and meso (school) levels.

However, in tandem with highlighting the importance of purpose as a critical starting point for developing a quality curriculum, understanding the issue of alignment was identified as essential. Using a socio-cultural framework (Fig. 5) this paper illustrates the complexity of alignment of purpose, policy (including curriculum, assessment, accountability and teacher professional learning) and practice between and within each level (Constitutive Order, School Arena, and Setting).

Three key challenges in achieving alignment were discussed, namely: stakeholder engagement, enhancing the professionalism of teachers, and developing better forms of summative assessment. Understanding and addressing these issues is essential in order to achieve alignment between purpose, policy and practice across levels of the school system.

The recent COVID-19 crisis has opened up debates and started to crystalise these issues. For example, clarifying one key purpose of schooling being to provide child care so that parents (and in particular 'essential workers') can go to work. Similarly, the replacement of high stakes tests in many countries (e.g. England, Scotland, Ireland, Australia, Slovakia) 
with alternative approaches to summatively assessing school leavers raises questions about the role of teacher assessments and opens the door for a wider debate about teacher professionalism and how best to judge students' learning.

Running through all three of the key issues explored in this paper is a tension between flexibility and control of the curriculum, and fundamentally the extent to which teachers are trusted. Perhaps the time is right, to move from what Hargreaves and Shirley (2009) describe as the Third Way - trust through control and accountability-to what they call the Fourth Way - trust based on a shared purpose, partnership, and teacher professionalism.

\section{References}

Alexander, R. (2010). Children, their world, their education: Final report and recommendations of the Cambridge primary review. Routledge: Abingdon.

Alexander, R. (2014). The best that has been thought and said. Forum., 56(1), 2014.

$\mathrm{Au}, \mathrm{W}$. (2011). Teaching under the new Taylorism: High-stakes testing and the standardization of the 21st century curriculum. Journal of Curriculum Studies, 43(1), 25-45.

Ball, S. J. (2008). Performativity, privatisation, professionals and the state. In B. Cunningham (Ed.), Exploring professionalism. London: Bedford Way Papers.

Berliner, D. (2011). Rational responses to high stakes testing: The case of curriculum narrowing and the harm that follows. Cambridge Journal of Education, 41(3), 287-302.

Biesta, G. (2004). Against Learning: Reclaiming a language for education in an Age of Learning. Nordisk Pedagogik, 23, 70-82.

Biesta, G., \& Priestley, M. (2013). Capacities and the curriculum. In M. Priestley \& G. Biesta (Eds.), Reinventing the curriculum: New trends in curriculum, policy and practice (pp. 35-49). London: Bloomsbury.

Biesta, G., Priestly, M., \& Robinson, S. (2015). The role of beliefs in teacher agency. Teachers and Teaching: Theory and practice, 21, 624-640.

Butler, D., Leahy, M., Twining, P., Akoh, B., Chtouki, Y., Farshadnia, S., et al. (2018). Education systems in the digital age: The need for alignment. Technology, Knowledge and Learning, 23(3), 473-494.

Conseil supérieur de l'éducation. (2018). Évaluer pour que ça compte vraiment, Rapport sur l'état et les besoins de l'éducation 2016-2018. Le Conseil: Québec.

Creese, B., Gonzalez, A., \& Isaacs, T. (2016). Comparing international curriculum systems: The international instructional systems study. Curriculum Journal, 27(1), 5-23.

Day, C. (2002). School reform and transitions in teacher professionalism and identity. International Journal of Educational Research, 37(8), 677-692.

Department of Education and Skills. (2017a). Digital learning framework for primary schools. Dublin: Department of Education and Skills. https://www.education.ie/en/Schools-Colleges/Information/ Information-Communications-Technology-ICT-in-Schools/digital-learning-framework-primary.pdf. Accessed 20 Apr 2020.

Department of Education and Skills. (2017b). Digital learning framework for post-primary schools. Dublin: Department of Education and Skills. https://www.education.ie/en/Schools-Colleges/Information/Infor mation-Communications-Technology-ICT-in-Schools/digital-learning-framework-post-primary.pdf. Accessed 20 Apr 2020.

Donaldson, G. (2015). Successful futures: Independent review of curriculum and assessment arrangements in Wales. Cardiff: Welsh Government.

Elliott, J. (1994). The teacher's role in curriculum development: An unresolved issue in English attempts at curriculum reform. Curriculum Studies, 2(1), 43-69.

Erstad, O., \& Voogt, J. (2018). The twenty-first century curriculum: issues and challenges. In J. Voogt, et al. (Eds.), Second handbook of Information Technology in Primary and Secondary Education (pp. 19-36). Springer International Handbooks of Education. doi:https://doi.org/10.1007/978-3-319-71054 $-9 \_1$. Accessed 20 Oct 2019.

ETAG. (2015). Education technology action group: Our reflections. https://etag.report. Accessed 21 Apr 2020.

European Commission. (2018). Commission staff working document accompanying the document proposal for a council recommendation on key competences for lifelong learning. Brussels: European Union. 
European Commission. (2019). Key competences for lifelong learning. Luxembourg: Publications Office of the European Union.

Fitzgerald, T., \& Knipe, S. (2016). Policy reform: Testing times for teacher education in Australia. Journal of Educational Administration and History, 48(4), 358-369.

Fluck, A., \& Hillier, M. (2016, September). Innovative assessment with eExams. Australian Council for Computers in Education Conference, Brisbane. https://www.researchgate.net/publication/31435 2356_Innovative_assessment_with_eExams. Accessed 21 Apr 2020.

Fullan, M. G., \& Miles, M. B. (1992). Getting reform right: What works and what doesn't. Phi delta kappan, 73(10), 745-752.

Giroux, H. (2002). Teachers as transformatory intellectuals. EDucate, 1(2), 46-49.

Giroux, H. A. (2010). In defense of public school teachers in a time of crisis. Policy Futures in Education, 8(6), 709-714.

Goodlad, J. (2006). What schools are for: Stimulating necessary dialogue for the reconstruction of schools in our democracy. Phi Delta Kappan International, Signature Edition.

Government of Alberta. (2019). Curriculum development. https://www.alberta.ca/curriculum-devel opment.aspx. Accessed 17 Apr 2013.

Hargreaves, A., \& Shirley, D. L. (2009). The Fourth Way: The inspiring future for educational change. Thousand Oaks (California): Corwin Press.

Kärkkäinen, K. (2012). Bringing about curriculum innovations (OECD Education Working Papers No. 82). Paris: OECD Publishing (NJ1).

Kelly, A. V. (2004). The curriculum: Theory and practice (5th ed.). London: Sage Publications.

Klenowski, V. (2015). Questioning the validity of multiple uses of NAPLAN data. In R. Lingard, G. Thompson, \& S. Sellar (Eds.), National Testing in Schools: An Australian assessment (pp. 44-56). London: Routledge.

Lawton, D. (1989). Education, culture and the national curriculum. London: Hodder and Stoughton.

Lave, J. (1988). Cognition in practice: Mind, mathematics and culture in everyday life. Cambridge: Cambridge University Press.

McCharen, B., Song, J., \& Martens, J. (2011). School innovation: The mutual impacts of organizational learning and creativity. Educational Management Administration \& Leadership, 39(6), 676-694.

McLaren, P., \& Farahmandpur, R. (2006). The pedagogy of oppression: A brief look at "no child left behinds',.' Monthly Review, 58(3), 94.

McLaughlin, M. (1990). The RAND change agent study revisited: Macro perspectives and micro realities. Educational Researcher, 19, 11-16.

OECD. (2018). The future of education and skills: Education 2030. Paris: OECD. https://www.oecd.org/ education/2030/E2030\%20Position\%20Paper\%20(05.04.2018).pdf. Accessed 11 Jul 2019.

OECD. (2019). Education at a glance 2019: OECD indicators. Paris: OECD Publishing.https://doi. org/10.1787/f8d7880d-en. Accessed 21 Apr 2020.

OECD. (2020).TALIS 2018 results (Volume II): Teachers and school leaders as valued professionalsParis: TALIS, OECD Publishing.https://doi.org/10.1787/19cf08df-en. Accessed 24 Apr 2020.

Ontwikkelteam Digitale Geletterdheid. (2019). Concept-eindproduct van het Ontwikkelteam Digitale geletterdheid. Den Haag: Curriculum.nu.

Orafi, S., \& Borg, S. (2009). Intentions and realities in implementing communicative curriculum reform. System, 37(2), 243-253.

Platform Onderwijs2032. (2016). Ons onderwijs2032: Eindadvies [Our Education 2032 - Final Recommendations]. Dan Haag: Platform Onderwijs2032. https://www.rijksoverheid.nl/binaries/rijksoverh eid/documenten/rapporten/2016/01/23/eindadvies-platform-onderwijs2032-ons-onderwijs2032/ eindadvies-platform-onderwijs2032-ons-onderwijs2032.pdf. Accessed 28 Apr 2020.

Pollard, A. (Ed.). (2010). Professionalism and pedagogy: A contemporary opportunity. A Commentary by TLRP and GTCE. London: TLRP.

Prendergast, M., \& Treacy, P. (2018). Curriculum reform in Irish secondary schools? A focus on algebra. Journal of Curriculum Studies, 50(1), 126-143.

Priestley, M. (2011). Schools, teachers, and curriculum change: A balancing act? Journal of educational change, 12(1), 1-23.

Priestley, M., Edwards, R., Priestley, A., \& Miller, K. (2012). Teacher agency in curriculum making: Agents of change and spaces for manoeuvre. Curriculum Inquiry, 42(2), 191-214.

Priestley, M., \& Biesta, G. (Eds.). (2013). Reinventing the curriculum: New trends in curriculum policy and practice. London: A \& C Black.

Priestley, M., \& Sinnema, C. (2014). Downgraded curriculum? An analysis of knowledge in new curricula in Scotland and New Zealand. Curriculum Journal, 25(1), 50-75. 
Robinson, K., \& Aronica, L. (2015). Creative schools: The grassroots revolution that's transforming education. London: Penguin Books.

Royal Netherlands Academy of Arts and Sciences [Koninklijke Nederlandse Akademie van Wetenschappen]. (2013). Digitale geletterdheid in het voortgezet onderwijs [Digital literacy in secondary education]. Amsterdam: KNAW.

Rubin, D. I. (2011). The disheartened teacher: Living in the age of standardisation, high-stakes assessments, and no child left behind (NCLB). Changing English, 18(4), 407-416.

Rubtcova, M., Pavenkov, O., Pavenkov, V., Martianova, N., \& Martyanov, D. (2015). Deprofessionalisation as a performance management dysfunction: The case of inclusive education teachers in Russia. Asian Social Science, 11(18), 339.

Schleicher, A. (2020). TALIS 2018: Insights and interpretations. TALIS: OECD Publishing, Paris.

Schoenfeld, A. H. (2014). What makes for powerful classrooms, and how can we support teachers in creating them? A story of research and practice, productively intertwined. Educational researcher, 43(8), 404-412.

Sinnema, C., \& Aitken, G. (2014). Teachers' use of research to improve practice: Why should we, how could we? In A. St George, S. Brown, O’Neill J (Eds.), Facing the big questions in teaching: Purpose, power and learning. North Shore: Cengage Learning.

Strijker, A. (2010). Leerlijnen en vocabulaires in de praktijk (Learning trajectories and vocabularies in practice). Enschede: Stichting Leerplanontwikkeling (SLO).

Taba, , H. (1962). Curriculum development: Theory and Practice. New York: Harcourt, Brace \& World.

Taguma, M., \& Barrera, M. (2019). OECD future of education and skills 2030: Curriculum analysis. Paris: OECD.

Tedesco, J. C., Opertti, R., \& Amadio, M. (2013). The curriculum debate: why it is important today (IBE Working Papers on Curriculum Issues No. 10). UNESCO International Bureau of Education. https://www.ibe.unesco.org/en/document/curriculum-debate-why-it-important-today-ibe-workingpapers-curriculum-issues-n\%C2\%B0-10

Teodoro, A., \& Estrela, E. (2010). Curriculum policy in Portugal (1995-2007): Global agendas and regional and national reconfigurations. Journal of Curriculum Studies, 42(5), 621-647.

Thijs, A., Fisser, P., \& van der Hoeven, M. (2014). 21e eeuwse vaardigheden in het curriculum van het funderend onderwijs [21st century skills in primary and secondary education]. Enschede: SLO.

Tikkanen, L., Pyhältö, K., Soini, T., \& Pietarinen, J. (2017). Primary determinants of a large-scale curriculum reform: National board administrators' perspectives. Journal of Educational Administration, 55(6), 702-716.

Tuinamuana, K. (2011). Teacher professional standards, accountability, and ideology: Alternative discourses. Australian Journal of Teacher Education (Online), 36(12), 72.

Twining, P. (2018, October). Educational alignment (and sociocultural theory). halfbaked.education Blog. https://halfbaked.education/educational-alignment-and-sociocultural-theory/. Accessed 21 Apr 2020.

Twining, P. (2019a, August). What should be learnt? halfbaked.education Blog. https://halfbaked.educa tion/what-should-be-learnt/. Accessed 21 Apr 2020.

Twining, P. (2019b, May). Characterisitcs of effective CPD. halfbaked.education Blog. https://halfb aked.education/characteristics-of-effective-cpd/. Accessed 7 Sep 2020.

Twining, P. (2019c, March). AI and Assessment - mining learning outcomes. halfbaked.education Blog. https://halfbaked.education/ai-and-assessment-mining-learning-outcomes/. Accessed 21 Apr 2020.

Twining, P. (2020a, November). Characteristics of effective summative assessment. halfbaked.education Blog. https://halfbaked.education/characteristics-of-effective-summative-assessment/. Accessed 10 Nov 2020.

Twining, P. (2020b, September). From standardised testing to living CVs. halfbaked.education Blog. https://halfbaked.education/from-standardised-testing-to-living-cvs/. Accessed 10 Nov 2020.

Twining, P., \& Henry, F. (2014). Enhancing 'ICT teaching' in English schools: Vital lessons. World Journal of Education, 4(2), 12-36. https://www.sciedu.ca/journal/index.php/wje/article/ view/4092/2502. Accessed 21 Apr 2020.

Twining, P., Browne, N., Murphy, P., Hempel-Jorgensen, A., Harrison, S., \& Parmar, N. (2017). NP3 New Purposes, New Practices, New Pedagogy: Meta-analysis report. Society for Educational Studies, London. http://oro.open.ac.uk/view/person/nb8738.html. Accessed 25 Jan 2018.

Twining, P., Rix, J., \& Sheehy, K. (2016). Developing point of learning: An innovative approach to enhancing professional learning. London: Imagine Education. https://www.researchgate.net/publi cation/313184671_Developing_Point_of_Learning_An_innovative_approach_to_enhancing_profe ssional_learning. Accessed 21 Apr 2020. 
United Nations General Assembly. (2015, September 25). Resolution 70/1: Transforming our world: the 2030 Agenda for Sustainable Development. https://www.un.org/ga/search/view_doc.asp?symbol=A/ RES/70/1\&Lang $=\mathrm{E}$

van den Akker, J. (2003). Curriculum perspectives: An introduction. In J. van den Akker, W. Kuiper, \& U. Hameyer (Eds.), Curriculum landscapes and trends (pp. 1-10). Dordrecht: Springer.

Voogt, J., \& ten Brummelhuis, A. (2014). Information literacy in the Netherlands: Rise, fall and revival. In A. Tatnall \& B. Davey (Eds.), Reflections on the history of computers in education: Early use of computers and teaching about computing in schools (IFIP advances in information and communications technology, Vol. 424, pp. 83-93). Berlin: Springer.

Walsh, T. (2018). Towards an overview of a redeveloped primary school curriculum: Learning from the past, learning from others. Dublin: National Council for Curriculum and Assessment.

Webb, M., \& Ifenthaler, D. (2018). Section Introduction: Using Information Technology for Assessement: Issues and opportunities. In J. Voogt, G. Knezek, R. Chirstensen, \& K. Lai (Eds.), Second Handbook of Information Technology in Primary and Secondary Education (Vol. 1, pp. 577-580). Cham (Switzerland): Springer.

Williamson, B. (2017). Coding for what? Lessons from computing in the curriculum. NAACE Advancing Education. https://mirandanet.ac.uk/blog/2017/09/02/coding-lessonscomputing-curriculum/

Wills, J. S., \& Sandholtz, J. H. (2009). Constrained professionalism: Dilemas of teaching in the face of testbased accountability. Teachers College Record, 111(4), 1065-1114.

Wolfenden, F., Buckler, A., Santos, C., \& Mittelmeier, J. (2018). Education workforce initiative: Initial research. Milton Keynes: The Open University.

Wong, B. W., \& Blandford, A. E. (2002). Analysing ambulance dispatcher decision making: Trialing emergent themes analysis. Proceedings of the HF2002 Human Factors Conference: Design for the Whole Person: Integrating Physical, Cognitive and Social Aspects. Ergonomics Society of Australia. Retrieved August 8, 2018, from https://discovery.ucl.ac.uk/16628/1/16628.pdf

World Bank. (2012). Systems approach for better education results - Finland - School Autonomy and accountability. Washington, DC: World Bank. https://openknowledge.worldbank.org/bitstream/handl e/10986/17510/799460WP0SABER0Box0379797B00PUBLIC0.pdf? sequence=1\&isAllowed=y. Accessed 21 Apr 2020.

Publisher's Note Springer Nature remains neutral with regard to jurisdictional claims in published maps and institutional affiliations.

Peter Twining is Professor of Education (Innovation in Schooling and Educational Technology) at the University of Newcastle (Australia). He has been Professor of Education (Futures) at the Open University (UK), Co-Editor in Chief for Computers \& Education, and the lead on a number of major projects looking at the use of digital technology both inside and outside formal education.

Deirdre Butler is a Professor in DCU's Institute of Education, whose passion in life is exploring what being digital in learning can mean and what skills or competencies are needed to live in today's complex globally connected world, challenging us to examine how we learn and questioning our assumptions about "traditional" models of schooling. She has designed and managed a range of projects / school-based initiatives which focus on sustainable, scalable models of teacher professional learning and creative uses of digital technologies.

Petra Fisser is currently working as educational advisor at the College of Health Care of ROC van Twente, a Regional Training Centre for Vocational Education and Training and Adult Education. Projects she is involved in are related to educational innovation of secondary vocational education and training (VET), adult education, and tailor-made courses for SME's. Before working at ROC van Twente, Petra worked at the National Institute for Curriculum Development and the University of Twente in the Netherlands, where she was engaged in projects, knowledge development and professional development in the field of curriculum development and evaluation, internationalization, digital literacy and TPACK.

Margaret Leahy is Head of the School of STEM Education, Innovation and Global Studies at the Institute of Education, DCU university. She has extensive experience in the theory and practice of digital learning, the design and development of professional learning programmes for teachers and has been involved in a range of innovations/research projects, all of which focus on ways digital technologies can be used to create more powerful learning environments. 
Chris Shelton is Head of Education within the Institute of Education, Health and Social Sciences at the University of Chichester where he is responsible for Education and Teacher Education programmes. Chris has a range of research interests relating to technology, computing and digital literacy in schools and universities. His recent work has included publications about teacher's thinking about technology in Higher Education; the pedagogy of teaching computing; and the curriculum.

Nadine Forget-Dubois has a Ph.D. in anthropology from the Université de Montréal and is a research agent at the Conseil supérieur de l'éducation du Québec, attached to the production of the Report on the states and needs of education.

Michel Lacasse is a doctoral candidate in education administration and policy at Université Laval. His thesis subject concerns the technological competence of school directors and, between theory and practice, he participates in various research projects in the field of education, which include school governance, alternative pedagogies, educational technologies and the training of teachers and administrators of education. 